\title{
Location and Structure of the var1 Gene on Yeast Mitochondrial DNA: Nucleotide Sequence of the 40.0 Allele
}

\author{
Michael E. S. Hudspeth, ${ }^{*}$ W. Michael Ainley, ${ }^{\dagger}$ \\ Deborah S. Shumard,* Ronald A. Butow ${ }^{\dagger}$ and \\ Lawrence I. Grossman* \\ * Department of Cellular and Molecular Biology \\ Division of Biological Sciences \\ The University of Michigan \\ Ann Arbor, Michigan 48109 \\ 'Department of Biochemistry \\ Division of Molecular Biology \\ The University of Texas Health Science Center at \\ Dallas \\ 5323 Harry Hines Boulevard \\ Dallas, Texas 75235
}

\section{Summary}

Alleles of the vary locus on yeast mitochondrial DNA specify the size of var1 ribosomal protein. We report the nucleotide sequence of a vart allele that determines the smallest var 1 protein. It contains an open reading frame of 396 codons, which we identify as the structural gene for var1 protein. The var 1 protein specified by this allele has an amino acid composition in close agreement with that predicted by the DNA sequence. The vart coding region is highly unusual: it is $89.6 \%$ AT and contains a 46 bp GC-rich palindromic cluster that accounts for $38 \%$ of the total GC residues. Our results strongly suggest that like mammalian mitochondria but unlike those from Neurospora, yeast mitochondria use AUA as a methionine codon. Comparison with the sequence of a vart allele specifying a larger protein suggests that some size polymorphism of var1 protein resuits from in-frame insertions of a variable number of AAT (Asn) codons.

\section{Introduction}

The mitochondrial genome of Saccharomyces cerevisiae has been well studied, since it lends itself to both genetic and physical analysis. At the nucleotide sequence level, the genes of six proteins have been analyzed thus far-cytochrome oxidase subunits I to III (Coruzzi and Tzagoloff, 1979; Fox, 1979; Bonitz et al., 1980b; Thalenfeld and Tzagoloff, 1980), cytochrome b (Nobrega and Tzagoloff, 1980) and ATPase subunits 9 and 6 (Macino and Tzagoloff, 1979, 1980 ) - as well as the 15S ribosomal RNA gene (Sor and Fukuhara, 1980) and numerous transfer RNA genes. In addition to the above genes, eight open but unassigned reading frames have been identified (Bonitz et al., 1980b; Dujon, 1980; Lazowska et al., 1980, 1981; Nobrega and Tzagoloff, 1980; Coruzzi et al., 1981), and all but one occur in introns of other genes.

Var1 is a mitochondrial translation product that is associated with the small subunit of yeast mitochondrial ribosomes (Groot et al., 1979; Terpstra and
Butow, 1979; Terpstra et al., 1979). Var1 protein has at least two unusual properties: it is polymorphic in different yeast strains (Douglas and Butow, 1976; Strausberg and Butow, 1981); and crosses between strains with two different var1 forms generate nonparental species, and do so with the characteristics of an asymmetric recombination event whereby "short" forms of the protein are converted preferentially to "long" forms (Strausberg et al., 1978; Strausberg and Butow, 1981).

The size polymorphism of var1 proteins and their recombination behavior in crosses have allowed us to define a series of var1 alleles (alleles are designated as $\operatorname{var} 1[n]$ or $[n]$, where $n$ is the apparent size, in kilodaltons $(k d)$, of the vart protein present in that allele; the proteins are designated as var1[n kd]), which we have mapped to a $2.6 \mathrm{~kb}$ segment of the yeast mitochondrial genome between ery (21S rRNA) and oli1 (ATPase 9). This region was previously termed the var1 determinant (Periman et al., 1977; Lopez et al., 1981; Strausberg and Butow, 1981). It contains strain-specific insertions and deletions, first detected by restriction mapping, some of which correlate with different forms of the var1 protein (Strausberg et al., 1978; Vincent et al., 1980; Vincent, 1982).

Tzagoloff et al. (1980) have reported the nucleotide sequence of the region between ery and oli1 in a petite strain (DS401, derived from wild-type strain D273-10B) that produces a var1 protein of intermediate size. They concluded that the structural gene for var1 protein could not be present in this region in a simple form because the region has a much higher AT content than any bona fide mitochondrial gene sequenced, and because no open reading frame exists that starts with a methionine codon and that extends for more than 37 amino acids. We recently attempted to rationalize their findings with our genetic and physical mapping data (Bitow et al., 1982).

We now report the nucleotide sequence of the var1[40.0] allele, which contains the smallest var1 protein seen to date, and compare this sequence with that of the [42.0] allele in DS401 (Tzagoloff et al., 1980), which specifies a var1 protein about $2 \mathrm{kd}$ larger. Our sequence in the var1 determinant region contains an open reading frame that starts with a methionine codon and runs sequentially for 396 amino acids to an ochre terminator. The amino acid composition predicted by the DNA sequence agrees closely with that determined from analysis of var1 protein, which we have purified to apparent homogeneity. Thus we identify this sequence as the structural gene for var1 protein. Its base composition of nearly $90 \%$ AT, with about one third of the GC content present as a single 46 bp cluster, makes it the most AT-rich gene we know of in nature. Results to be presented elsewhere (M. E. S. Hudspeth, R. D. Vincent, L. O. Treisman, D. S. Shumard, P. S. Perlman and L. I. Grossman, manuscript in preparation) describe DNA inser- 
tions within the reading frame of var1[40.0] in strains producing larger var1 proteins.

\section{Results}

\section{Restriction Map of Petite A17-10 and Sequencing Strategy}

The mitochondrial DNA (mtDNA) of petite A17-10 was shown by Vincent et al. (1980) to be a $5.3 \mathrm{~kb}$ headto-tail repeat. From transmission analysis and zygotic gene-rescue analysis (Strausberg and Butow, 1977; Vincent et al., 1980; Lopez et al., 1981), we know that A17-10 mtDNA contains the entire var1 determinant region located within a $2.7 \mathrm{~kb}$ fragment corresponding to Hinc II band 10 of the wild-type genome. The restriction map of A17-10 mtDNA has been extended with ten additional enzymes to show fine structure (Hudspeth et al., manuscript in preparation), and a summary of that map for Hinc II band 10 is shown in Figure 1.

The strategy used for sequencing the open reading frame is shown in Figure 2. This figure shows the fragments that were labeled at either their $5^{\prime}$ or $3^{\prime}$ termini and the manner in which the labeled ends were made asymmetric. All of the sites labeled for sequencing within the coding region were crossed at least once from other labeled ends, except for the $\mathrm{Bcl} I$ site.

\section{Nucleotide Sequence of the var1[ 40.0] Allele}

The sequence of the open reading frame of the [40.0] allele is shown in Figure 3. It encodes 396 amino acids, or a protein of molecular weight 46,786 . This value is in reasonable agreement with a molecular weight of 40,000 estimated by SDS-polyacrylamide gel electrophoresis for the protein specified by the var1[40.0] allele (Perlman et al., 1977; Strausberg and Butow, 1981). We note that underestimates of protein size by SDS-polyacrylamide gel electrophoresis for other mitochondrially encoded proteins have been observed. For instance, sizes of human cytochrome oxidase subunits I-III were underestimated by $21 \%-40 \%$ compared with the protein sizes derived from DNA sequencing (Hare et al., 1980; Anderson et al., 1981). Similar underestimates have been seen for

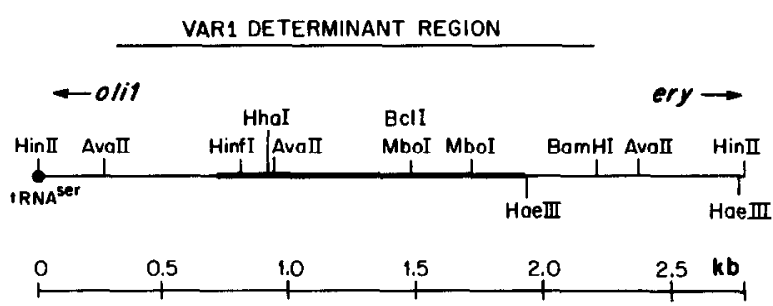

Figure 1. Restriction Map of the vart Determinant Region

Hinc II fragment 10 of wild-type mtDNA is shown with selected restriction sites. tRNA ${ }^{\text {Ser }}$ is from Tzagoloff et al. (1980). The vart determinant region was defined by gene rescue with petite mutants; the ends of the region between Ava II and Hinf I, and between Hae III and Bam HI, are not defined. Thick line: open reading frame. yeast mitochondrial proteins (Groot et al., 1978; Bonitz et al., 1980b).

The reading frame in var1 is on the same strand as most other genes on yeast mtDNA. Analysis of var1 transcripts $(H$. P. Zassenhaus, $Y$. Hannon and R. A. Butow, manuscript in preparation) confirms this assignment and shows that transcription is in the direction oli1 to ery. However, unlike other yeast mitochondrial genes and unassigned open reading frames, the var1 sequence is $89.6 \% \mathrm{AT}$, with more than one third of the GC concentrated in a 46 bp palindromic cluster starting at nucleotide 198 in Figure 3.

\section{Purification of the var1[40.0 kd] Protein, and Amino Acid Analysis}

For amino acid analysis, we purified var1 protein in essentially homogeneous form directly from SDSpolyacrylamide gels (see Experimental Procedures). The var1 protein is tightly associated with the 385 mitochondrial ribosomal subunit (Terpstra et al., 1979), and therefore can easily be purified away from the bulk of mitochondrial proteins. Figure 4 shows that var1 protein is well resolved from the other 385 ribosomal proteins by both one- and two-dimensional gel electrophoresis. Figure 4 also shows a typica preparation of var1 protein, purified from 385 subunits, that migrates as a single band on an $11 \%$ SDSpolyacrylamide gel. Displayed on the same gel is a profile of mitochondrial translation products labeled in vivo in the presence of cycloheximide with ${ }^{35} \mathrm{SO}_{4}{ }^{2-}$ (Douglas and Butow, 1976), showing that the labeled var1 comigrates with purified var1 protein and with var1 from the $38 \mathrm{~S}$ ribosomal subunit. The determination of amino acid composition of purified var1 protein was carried out as described in the Experimental Procedures; the results are presented in Table 1.

\section{Assignment of the Open Reading Frame as var1} The amino acid sequence specified by the open reading frame is also shown in Figure 3; its composition is summarized in Table 1. For translation we have used the previously noted modifications of the universal

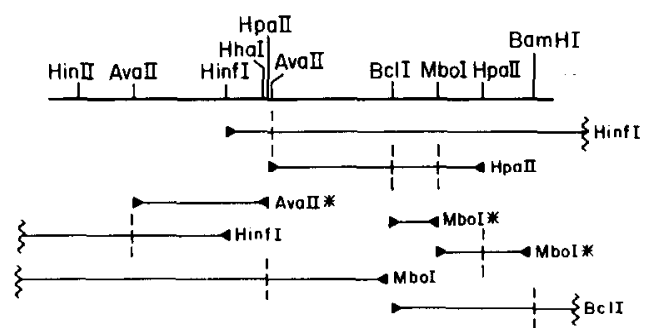

Figure 2. Labeling Strategy for Sequencing var1[40.0]

A portion of Hinc II fragment 10 (Figure 1) is shown. The fragments were digested with the indicated enzymes and labeled at their $5^{\prime}$ or $3^{\prime}$ ends, and the labeled ends were segregated by strand separation (asterisks) or by secondary cleavages (vertical dashed lines). Vertical wavy lines: the fragment extends beyond the map portion shown. 
* met lys leu lys leu leu asn met ile leu ser met met asn lys thr asn asn asn asn asn ile TAAAAAATAATG AAA TTA AAA TTA TTA AAT ATA ATT TTA TCA ATA ATA AAT AAA CTT AAT AAT AAT AAT AAT ATT ile ile asn asn thr leu asp ser leu met asn lys lys leu leu leu lys asn met leu leu asp met asn asn ATT AIT AAT AAT CTA TIA GAT TCA TTA ATA AAT AAG AAA TTA TTA ITA AAG AAT ATA TTA TTA GAT ATA AAT AAT 150

lys lys met asn asn met lys arg met leu asn asn asn asn met asn pro ald gly ala asn pro val val his AAA AAA ATA AAT AAT ATA AAA AGA ATA TTA AAT AAT AAT AAT ATA AAC CCC GCG GGC GCC AAT CCG GIT GTT CAC 22

arg ile gly pro ala gly asn ile asn asn lys leu gln his leu asn asn met asn asn trp asn thr gln ile CGG ATT GGT CCC GCG GGG AAT ATT AAT AAT AAA TTA CAA CAT TTA AAT AAT ATA AAT AAT IGA AAT CIA CAA ATT 300

tyr asn tyr asn lys asn met glu ile met asn thr met asn asp lys leu ile asn lys leu leu tyr lys met TAT AAT TAT AAT AAA AAT ATA GAA ATT ATA AAT ACT ATA AAT GAT AAA TTA ATT AAT AAA TTA TTA TAT AAA ATA met thr leu lys leu asn asn met asn ile asn lys ile ile met ser lys thr ile asn gln nis ser leu asn ATA ACT TTA AAA TTA AAT AAT ATA AAT ATT AAT AAA ATT ATT ATA AGT AAA CTT ATT AAT CAA CAT AGT TTA AAT 450

lys lew asn ile lys phe tyr tyr tyr asn asn asp ile asn asn asn asn asn asn asn asn tyr tyr met asn AAA TTA AAT ATT AAA TTT IAT TAT TAT AAT AAT GAT ATT AAT AAT AAT AAT AAT AAT AAT AAT, TAT TAT ATA AAT 525 met met asn lys leu met asn ile met asn asn asn met asn asn asn leu cys asn lle leu ser tyr tyr tyr ATA ATA AAT AAA TTA ATA AAT ATT ATA AAT AAT AAT ATA AAT AAT AAT TTA TGT AAT ATT TTA AGT TAT TAT TAT 600

asn lys lys val thr ile glu pro ile lys leu ser tyr ile tyr leu asn ser asp ile phe ser lys tyr ile AAT AAA AAA GTA ACT ATT GAA CCT ATT AAA TTA TCA TAT ATT TAT TTA AAT AGT GAT ATT TTT AGT AAA TAT ATT 675

ser leu asn asp met asp lys tyr asn asn gly ile leu thr asn tyr gin arg met leu asn asn ile met pro AGT TTA AAT GAT ATA GAT AAA TAT AAT AAT GGT ATC TTA ACT AAT TAT CAA CGT ATA TTA AAT AAT ATT ATG CCT 750

lys leu asn asp his asn ile ser met asn tyr ile asn asn ile asn asn ile asn asn asn lys tyr asn asn AAA TTA AAT GAT CAT AAT ATT TCT ATA AAT TAT ATT AAT AAT ATT AAT AAT ATT AAT AAT AAT AAA TAT AAT AAT 825

met ile asn leu leu asn asn asn asn asn ile asn asn asn asn asn tyr asn asn asn asn asn asn tyr ile ATA ATT AAT TTA TTA AAT AAT AAT AAT AAT, ATT AAT AAT AAT AAT AAT TAT AAT AAT AAT AAT AAT AAT TAT ATT 900

gly asn ile asn asn ile tyr asn asn met thr ile asp asn ile pro met asp ile leu met tyr lys tyr leu GGT AAT ATT AAT AAT ATT TAT AAT AAT ATA ACT ATT GAT AAT ATT CCT ATA GAT ATT TTA ATA TAT AAA TAT TTA 975

val gly trp ser ile lys phe lys gly arg leu ser asn asn asn gly arg thr ser thr thr asn leu leu asn GTT GGT TGA TCT ATT AAA TTT AAA GGT AGA TTA AGT AAT AAT AAT GGT AGA ACT AGT ACA CTT AAT TIA TTA AAT 1050

gly thr phe asn asn lys lys tyr leu trp ser asn ile asn asn asn tyr lys leu asn tyr ile pro ser asn GGT ACT TTT AAT AAT AAA AAA TAT TTA TGA AGT AAT ATT AAT AAT AAT TAT AAA TTA AAT TAT ATC CCT TCT AAT 1125

his asn leu tyr asn asn ser asn ile asn lys asn gly lys tyr asn ile lys val lys leu asn phe ile * CAT AAT TTA TAT AAT AAT ICT AAT ATT AAT AAA AAT GGT AAA TAT AAT ATT AAA GTT AAA TTA AAC TTT ATT TAA 1200 Figure 3. Nucleotide Sequence of the var1[40.0] Open Reading Frame

The sequence shown is of the nontranscribed strand, with the $5^{\prime}$ end at the upper left. Asterisks: ochre triplets. The sequence is translated with the yeast mitochondrial genetic code (Bonitz et al., 1980a). In addition, ATA has been translated as methionine (see text). Underlining: substitutions compared with the [42.0] allele sequence. Double underlining: insertions. Brackets: acceptor regions for the allele-specific insertions (see text)

genetic code (Bonitz et al., 1980a) that UGA signifies tryptophan and CUN signifies threonine, as well as the assumption (see below) that AUA encodes methionine. As anticipated from its base composition, the open reading frame specifies a low proportion of amino acids encoded by GC-rich codons and is well represented by amino acids encoded by AT-rich codons. Particularly striking is the extraordinary number of asparagines, which represent nearly one third of the total amino acid residues.

A comparison of the amino acid composition of purified var1[40.0 kd] protein with the composition specified by the DNA sequence shows a close correspondence between the predicted and experimentally determined values (Table 1). Using a simple algorithm (Cornish-Bowden, 1978) to estimate the extent of amino acid sequence identity between two proteins of equal length from their amino acid composition, we calculate a $93 \%$ probability of sequence identity between the protein specified by the var 1 open reading frame and the var1[40.0 kd] protein. This agreement, considered particularly in light of the very unusual amino acid composition predicted by the var1 sequence, argues strongly that the var1 protein is encoded by the open reading frame in the var 1 determinant region.

Additional support for the assignment to the open reading frame comes from preliminary radiochemical sequencing of the var1[42.0 kd] protein labeled in vivo with ${ }^{35} \mathrm{SO}_{4}{ }^{2-}(\mathrm{H}$. P. Chiang and $\mathrm{R}$. A. Butow, unpublished results), showing a correspondence between the position of methionine residues at the amino end (assuming AUA as a methionine codon; see below) and the distribution of radioactive sulfur.

\section{Assignment of AUA As a Methionine Codon}

Translation of the open reading frame with the standard genetic code that has been modified solely by the assignment of UGA as tryptophan and of CUN as threonine (Bonitz et al., 1980a) provides only two significant disagreements ( $>5$ mean deviations) with the measured amino acid composition: methionine is 


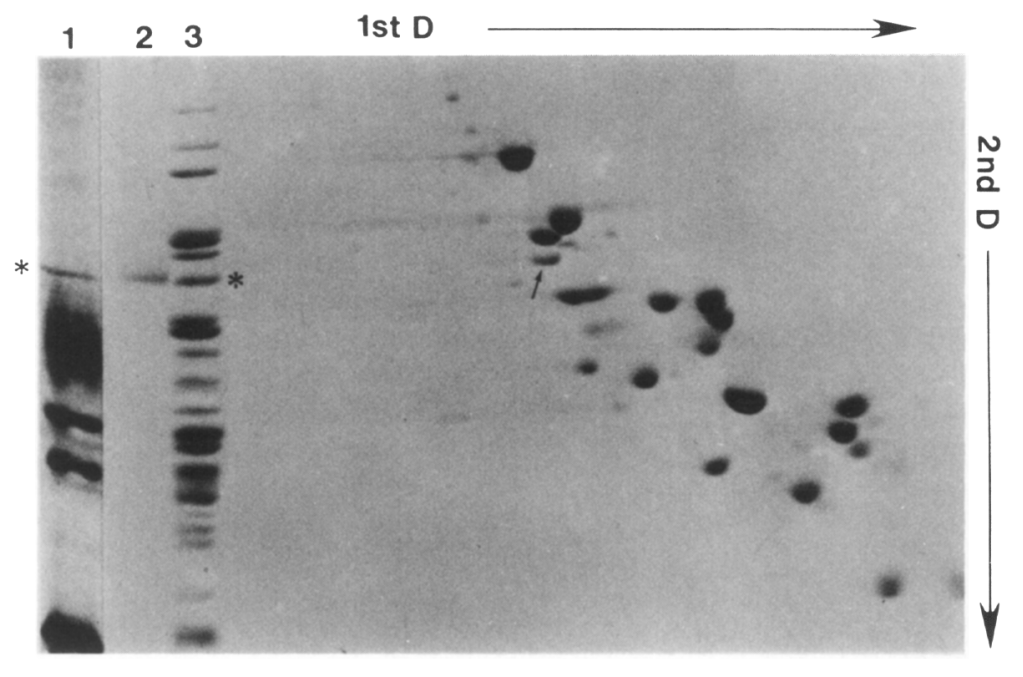

Figure 4. Electrophoretic Analysis of Purified var1 Protein: Comparisons with 385 Mitochondrial Ribosomal Proteins and in Vivo-Labeled Mitochondrial Translation Products

(Lanes 1-3) Samples were subjected to electrophoresis on an $11 \%$ SDS gel and autoradiographed. (Lane 1) Mitochondrial translation products labeled in vivo with ${ }^{35} \mathrm{SO}_{4}{ }^{2-}$; (lane 2) purified var1 protein; (lane 3) 385 mitochondrial ribosomal proteins. Except for lane 1, proteins were visualized by staining with Coomassie blue. Two-dimensional gel electrophoresis of the 385 mitochondrial ribosomal proteins was carried out as described in the Experimental Procedures. Lanes $1-3$ were run on the same gel as the second dimension (2nd D) of the two-dimensional gel. Asterisks and arrow: var1.
Table 1. Amino Acid Composition of Purified var1 Protein Agrees Closely with the Composition Predicted from the var1 DNA Sequence

\begin{tabular}{lcc}
\hline & \multicolumn{2}{c}{ Composition (mole \%) } \\
\cline { 2 - 3 } Amino Acid & $\begin{array}{l}\text { Calculated } \\
\text { from DNA }\end{array}$ & $\begin{array}{c}\text { Determined } \\
\text { from Protein }\end{array}$ \\
\hline Alanine & 0.8 & 1.3 \\
Arginine & 1.3 & 1.1 \\
Aspartic acid + asparagine & 35.3 & 36.0 \\
Glycine & 2.6 & 2.7 \\
Glutamic acid + glutamine & 1.6 & 2.3 \\
Histidine & 1.3 & 1.3 \\
Isoleucine & 10.9 & 10.5 \\
Leucine & 10.6 & 11.3 \\
Lysine & 9.6 & 9.4 \\
Methionine & 8.6 & 6.9 \\
Phenylalanine & 1.3 & 1.4 \\
Serine & 4.2 & 3.9 \\
Threonine & 3.4 & 3.2 \\
Tyrosine & 7.3 & 7.4 \\
Valine & 1.3 & 1.4 \\
\hline The amino acid composition & & \\
\hline
\end{tabular}

The amino acid composition derived from DNA was translated with the assumptions that CUN encodes threonine and AUA encodes methionine (see text). Cysteine, proline and tryptophan were not determined in the protein sequence and were not used in the calculation of composition (mole \%) from DNA. The values determined from protein are averaged from 15 and 24 hr hydrolyses.

predicted to constitute 0.5 mole $\%$ and is found to be 6.9 mole \%, and isoleucine is predicted to be 18.4 mole \% and is found to be 10.5 mole \%. Both discrepancies are resolved if AUA is assigned as a methionine rather than an isoleucine codon (Table 1).

The assignment of AUA to methionine, which increases the symmetry of the AUN box of the genetic code table, was previously suggested for the human and bovine mitochondrial genetic codes by comparison of the amino acid sequences from DNA with the amino acid sequence of bovine cytochrome oxidase subunit II (Barrell et al., 1979; Young and Anderson, 1980). We thus suggest that AUA represents methionine in yeast mitochondria as well. As shown in Table 2 , AUA is used for 31 of the 33 residues assigned as methionine, while AUG is used only once internally. The use of AUA for Met by other yeast mitochondrial genes, but not by Neurospora mtDNA (Browning and RajBhandary, 1982), is examined in the Discussion.

\section{Other Codon Usage}

Table 2 also lists the use of other codons in var1, and compares var1 with other yeast mitochondrial genes, and with mitochondrial open reading frames unassigned to any proteins. In all of the data, the clear pattern is for the use of the most $\mathrm{AU}$-rich codons in both genes and open reading frames, consistent with the low GC content of yeast mtDNA. Within this overall pattern, several additional trends can be seen. It has already been noted that arginine codons of the CGN series are found in open reading frames, but have not been seen in established genes, and that phenylalanine codons are about equally divided between UUU and UUC in genes, but strongly biased toward UUU in open reading frames (Bonitz et al., 1980b). A similar bias is seen here in the use of AUG and AUA codons for methionine. The use of codons by var1 resembles that of open reading frames by these criteria. In addition, we note that where a choice is possible, the var1 gene uses codons ending in $U$ rather than $A$, although the nontranscribed strand contains a $10 \%$ excess of $A$ over $T$.

\section{Comparison with the [42.0] Allele Sequence}

Our sequence of var1[40.0] differs in three ways from the sequence reported for the [42.0] allele by Tzagoloff et al. (1980). 


\begin{tabular}{|c|c|c|c|c|c|c|c|c|c|}
\hline Amino Acid & Codon & Genes $^{a}$ & $\mathrm{ORF}^{\circ}$ & var1 & Amino Acid & Codon & Genes $^{\mathrm{a}}$ & $\mathrm{ORF}^{\mathrm{b}}$ & vart \\
\hline \multirow[t]{5}{*}{ Ala } & GCA & 53 & 30 & 0 & Lys & AAA & 31 & 352 & 35 \\
\hline & u & 66 & 58 & 0 & & G & 1 & 26 & 2 \\
\hline & C & 5 & 10 & 1 & & & & & \\
\hline & G & 2 & 7 & 2 & Met $^{c}$ & AUA & 7 & 133 & 31 \\
\hline & & & & & & G & 65 & 49 & 2 \\
\hline \multirow[t]{7}{*}{ Arg } & AGA & 37 & 121 & 3 & & & & & \\
\hline & $\mathbf{G}$ & 0 & 7 & 0 & Phe & UUU & 71 & 136 & 5 \\
\hline & CGA & 0 & 0 & 0 & & C & 60 & 19 & 0 \\
\hline & u & 0 & 14 & 1 & & & & & \\
\hline & C & 0 & 1 & 0 & Pro & $\mathrm{CCA}$ & 35 & 26 & 0 \\
\hline & G & 0 & 1 & 1 & & u & 39 & 63 & 4 \\
\hline & & & & & & C & 2 & 5 & 2 \\
\hline \multirow[t]{3}{*}{ Asn } & AAU & 62 & 356 & 124 & & G & 0 & 8 & 1 \\
\hline & C & 9 & 26 & 2 & & & & & \\
\hline & & & & & Ser & UCA & 71 & 71 & 3 \\
\hline \multirow[t]{3}{*}{ Asp } & GAU & 41 & 137 & 10 & & u & 34 & 68 & 4 \\
\hline & C & 2 & 9 & 0 & & C & 1 & 10 & 0 \\
\hline & & & & & & G & 0 & 3 & 0 \\
\hline \multirow[t]{2}{*}{ Cys } & UGU & 12 & 53 & 1 & & AGU & 15 & 67 & 9 \\
\hline & C & 1 & 1 & 0 & & C & 0 & 3 & 0 \\
\hline \multirow[t]{3}{*}{ Gin } & CAA & 29 & 69 & 4 & Thr & $A C A$ & 51 & 76 & 1 \\
\hline & G & 4 & 7 & 0 & & u & 34 & 62 & 7 \\
\hline & & & & & & C & 1 & 12 & 0 \\
\hline \multirow[t]{3}{*}{ Glu } & GAA & 37 & 105 & 2 & & $\mathbf{G}$ & 0 & 17 & 0 \\
\hline & G & 3 & 16 & 0 & & CUA & 14 & 24 & 2 \\
\hline & & & & & & u & 2 & 21 & 3 \\
\hline \multirow[t]{5}{*}{ Gly } & GGA & 28 & 52 & 0 & & C & 0 & 1 & 0 \\
\hline & U & 88 & 120 & 8 & & $\mathbf{G}$ & 2 & 0 & 0 \\
\hline & c & 0 & 6 & 1 & & & & & \\
\hline & G & 6 & 14 & 1 & Trp & UGA & 36 & 47 & 3 \\
\hline & & & & & & G & 0 & 6 & 0 \\
\hline \multirow[t]{3}{*}{ His } & CAU & 47 & 65 & 4 & & & & & \\
\hline & C & 3 & 3 & 1 & Tyг & UAU & 73 & 209 & 28 \\
\hline & & & & & & C & 13 & 17 & 0 \\
\hline \multirow[t]{3}{*}{$11 e^{c}$} & AUU & 149 & 270 & 40 & & & & & \\
\hline & C & 26 & 22 & 2 & Val & GUA & 76 & 89 & 1 \\
\hline & & & & & & U & 42 & 66 & 4 \\
\hline \multirow[t]{2}{*}{ Leu } & UUA & 224 & 338 & 41 & & C & 4 & 4 & 0 \\
\hline & G & 2 & 13 & 0 & & G & 6 & 10 & 0 \\
\hline
\end{tabular}

Data are given as number of occurrences of the codons in the genes listed.

Data for genes are for oli1, oli2, oxi1, oxi2 and the exons of oxi3 and cob-box.

Data for the open reading frames (ORF) are from seven intron-encoded reading frames in omega, oxi3 and cob-box, and one free-standing open reading frame near oxi1 (Coruzzi et al., 1981).

' AUA is assigned as a methionine codon (see text).

First, in both the var1 [40.0] and [42.0] alleles, the orientation of the small Mbo I-Mbo I fragment (Figure 1 ) is that given by the sequence of Figure 3, and not the inverted orientation given by Tzagoloff et al. (1980). This conclusion is based on our sequence of the Mbo I-Mbo I fragment, carried out from the unique Bcl I site, which we mapped to the position shown in Figure 1. We note that the Bcl I site can be seen in the published sequence of DS401 at the same position as in Figure 1, and that its location there is independent of the orientation of the Mbo I-Mbo I fragment. More- over, we have recently sequenced a portion of a cDNA synthesized from a var1 [40.0] transcript (Zassenhaus et al., manuscript in preparation), and find complete agreement with the orientation and sequence of the Mbo I-Mbo I segment shown here.

Second, our var1 sequence contains a total of two insertions and four substitutions compared with the [42.0] allele given by Tzagoloff et al. (1980); these differences are underlined in Figure 3 . Of the latter, two result in amino acid substitutions at positions 92 (Ser to Leu) and 1005 (Ser to Arg) (Figure 3), one is 
silent (position 441) and the remaining substitution removes a termination codon (position 436). To resolve these differences, we determined the sequence of a segment of the var1 region in petite DS401 whose published sequence differs from our [40.0] sequence by one insertion and two base changes (at bases 436 , 441 and 469 in Figure 3). Our sequence of that segment of DS401 was identical to the sequence in Figure 3. Because of these corrections, we can reconcile the discrepancy between our finding of a continuous reading frame in the var1 [40.0] allele and the apparent absence of such an open reading frame in the [42.0] allele sequenced by Tzagoloff et al. (1980).

Third, our sequence lacks two groups of nucleotides whose presence does not shift the reading frame, and that we believe to be allele-specific elements responsible for the size of var1 protein in various strains: one is a 6 base sequence found after nucleotide 489 in Figure 3, and the other is an 18 base sequence found after nucleotide 840 (compare Tzagoloff et al., 1980). These regions are bracketed to indicate that the exact points of insertion are indeterminate. Both inserts are repeats of AAT (Asn) codons and thus lengthen the product of the [42,0] allele by a total of 8 asparagine residues compared with that of the [40.0] allele. These inserts were called $b$ elements in previous genetic studies of the var 1 region (Strausberg and Butow, 1981). A further analysis of these inserts, in addition to other inserts we have uncovered in different var1 alleles, will be presented elsewhere (Hudspeth et al., manuscript in preparation).

\section{Discussion}

We have identified a long open reading frame in a region of yeast mtDNA previously shown to contain the determinant specifying the size of var1 protein (Strausberg et al., 1978; Vincent et al., 1980). Based on the location of this open reading frame, the close agreement between the amino acid compositions in Table 1 and the agreement between the derived $\mathrm{N}$ terminal sequence and the preliminary amino acid sequence data cited in the Results, we conclude that the open reading frame represents the structural gene for var1 protein. Although we cannot eliminate the possibility of one or more introns within the coding region, the very close agreement between the amino acid composition predicted from the DNA sequence and that found for the protein makes the presence of extensive intervening sequences unlikely.

Additional evidence for the expression of the open reading frame comes from our identification of specific transcripts of this entire sequence and some $1 \mathrm{~kb}$ of flanking DNA (Farrelly et al., 1982). In particular, we have found that the putative mRNA for var1 protein, a $16 S$ RNA species, varies in a strain-dependent manner in both size and amount in direct correspondence with the size and amount of var1 protein made. Furthermore, all of the inserts we have identified in the coding region associated with specific var1 alleles (Hudspeth et al., manuscript in preparation) are found in the $16 \mathrm{~S}$ var1 transcript (Zassenhaus et al., manuscript in preparation).

\section{Assignment of the AUA Codon}

The agreement between amino acid compositions, and between predicted and preliminary $\mathrm{N}$-terminal amino acid residues, suggests an alteration in the currently used yeast mitochondrial genetic code (Bonitz et al., 1980a) to allow AUA to be read as methionine. This alteration has already been noted for the human (Barrell et al., 1979), bovine (Young and Anderson, 1980) and murine (Bibb et al., 1981) mitochondrial genomes. On yeast mtDNA, other than its occurrence in var1, ATA is used a total of seven times in the six protein-coding genes previously sequenced (see Introduction). In the gene encoding cytochrome oxidase subunit I (Bonitz et al., 1980b), the single use of the ATA codon is found in a protein fragment strongly homologous (13 of 17 residues) to its bovine analog, in which that position is occupied by methionine (Figure 5). Methionine is also predicted in the analogous position on human and murine mtDNAs. Of the other six uses of ATA in yeast mitochondrial genes, in five the homologous position in human, bovine or murine mtDNA is occupied by nelther methionine nor isoleucine. In the remaining case (in the gene encoding cytochrome oxidase subunit II), the analogous position is in a region of low homology ( 2 of 17 residues) and is filled by isoleucine on murine and bovine mtDNAs, but by leucine in human mtDNA.

The gene encoding cytochrome oxidase subunit III on Neurospora crassa mtDNA has recently been sequenced (Browning and RajBhandary, 1982). Comparison of the amino acid composition derived from the DNA sequence with that determined for the protein (Sebald et al., 1973) indicates that the AUA codon in Neurospora mitochondria is translated conventionally as isoleucine. In addition, those data support the conventional use of the CUN series for leucine, although our results are consistent with the exceptional use of CUN for threonine in yeast mitochondria (Bonitz

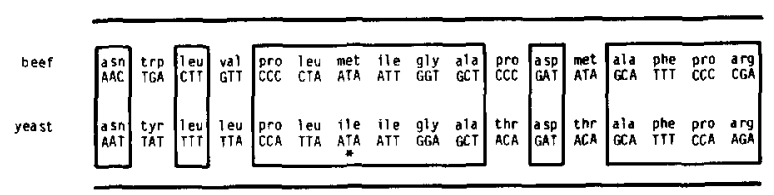

Figure 5. Comparison of Portions of Yeast and Bovine Genes Encoding Cytochrome Oxidase Subunit I

The bovine sequence (Anderson et al., 1982) represents nucleotides 5924-5974. The yeast sequence (Bonitz et al., t980b) represents nucleotides 5204-5206 and 6721-6769; these sequences are separated by intron sequences. Asterisk: the ATA codon. Boxes: regions of amino acid homology. 
et al., 1980a). These comparisons show a startling split in the mitochondrial genetic code among members of the class Ascomycetes. Taken together with the finding that the gene encoding ATPase subunit 9 is on mtDNA in yeast but on nuclear DNA in Neurospora (Sebald et al., 1977; Macino and Tzagoloff, 1979), and that var1 and its cognate protein from Neurospora, S-5, appear unrelated (see below), they suggest that similar organisms have taken parallel but nonidentical paths in the evolution of their mitochondrial genomes.

The recent sequencing of the gene encoding cytochrome oxidase subunit II in Zea mays (Fox and Leaver, 1981) allows the use of ATA in plant mitochondrial genomes to be addressed as well. Unfortunately, the single use of ATA in that gene occurs at a position that in the human protein is occupied by leucine in a region of modest but recognizable homology ( 6 of 17 residues), and that in bovine (Anderson et al., 1982), murine (Bibb et al., 1981) and yeast (Coruzzi and Tzagoloff, 1979; Fox, 1979) proteins is occupied by leucine, leucine and phenylalanine, respectively. Thus the position specified by ATA in $Z$. mays is weakly conserved, and is occupied by neither methionine nor isoleucine in the available comparisons.

\section{Proteins Related to var1}

Var1 has been shown to be a protein of the small mitochondrial ribosomal subunit, and it has been suggested that it has a role in the assembly of mitochondrial ribosomes (Terpstra and Butow, 1979). Do other mitochondria contain an analogous protein? Neurospora (Lambowitz et al., 1976, 1979), and probably Paramecium (Tait et al., 1976) and Tetrahymena (Perasso et al., 1980), contain a mitochondrially synthesized mitochondrial ribosomal protein. Of these, the Neurospora protein, S-5, has been purified and partially characterized (LaPolla and Lambowitz, 1981). Although the gene for this protein has not been identified, it is presumed to be on Neurospora mtDNA. However, in spite of the similarity in size between S-5 and var1, their amino acid compositions are clearly unrelated. For instance (compare with Table 1), S-5 contains $12.2 \%$ aspartic acid plus asparagine, $0.4 \%$ methionine, $8.1 \%$ alanine and $7.3 \%$ glutamic acid plus glutamine (LaPolla and Lambowitz, 1981). One consequence of this difference is that var 1 is considerably less polar than S-5 (23\% hydrophilic amino acids versus $50 \%$, respectively) and, interestingly in this respect, is more like a "typical" mitochondrial translation product than a ribosomal protein.

Although experiments with inhibitors of mitochondrial protein synthesis implicate both S- 5 and var 1 in the assembly of mitochondrial ribosomes (LaPolla and Lambowitz, 1977; Lambowitz et al., 1979; Terpstra and Butow, 1979), they may be unrelated and structurally different ribosomal proteins. Possibly, any one of a number of mitochondrial ribosomal proteins, if synthesized in mitochondria, can function equivalently in ribosome assembly.

In this connection, we have searched for homology between the predicted sequence of var1[40.0 kd] protein and that of each of the unidentified reading frames in human mtDNA (Anderson et al., 1981) without finding a match. Since only a minority of the $\mathbf{2 5}$ or so mitochondrial translation products detected in HeLa mitochondria (Attardi et al., 1980) have been assigned to known genes, the presence of a mitochondrially translated ribosome-associated protein in higher eucaryotes remains an open question.

If a var1-like protein is necessary for mitochondrial function, we can envision two possible explanations for the lack of homology: one is that var1 is evolving too rapidly for homology in amino acid sequence to be evident by the comparisons we have made, and a second is that yet a different mitochondrial ribosomal protein is translated in human mitochondria. Alternatively, if such a protein need not be translated within mitochondria, then the gene for a var1-like protein in human mitochondria may be nuclear-encoded. The latter explanation is analogous to the observation that the gene for ATPase 9 is present on mtDNA in yeast (Macino and Tzagoloff, 1979) but on nuclear DNA in Neurospora (Sebald et al., 1977).

\section{Codon Usage in vart}

As seen in Table 2, a number of codons are not used at all, and these are heavily skewed towards codons containing a $\mathrm{G}$ or $\mathrm{C}$ in the third position in place of an $A$ or U. Bonitz et al. (1980b) first noted that CGN arginine codons have not been found in established genes, but are found in open reading frames, and that phenylalanine is encoded about equally by UUU and UUC in genes, but is strongly biased toward UUU in open reading frames (Table 2 ). In addition, with our reassignment of the AUA codon, methionine is specified by AUG preponderantly in genes and by AUA preponderantly in open reading frames. Interestingly, var1 resembles open reading frames rather than genes in all three properties.

The significance of such observations about codon usage is unclear. There seems to be no a priori reason why codon usage should reflect the order in which investigators identify gene products. We can speculate instead that genes with open reading frames represent the past colonization of mitochondria by a different group of genes than those that participate in oxidative phosphorylation. This argument suggests that fungi were colonized at least twice, and that the marked differences in codon usage reflect these independent events.

\section{Organization of the Yeast Mitochondrial Genome} The open reading frame in var1 is $89.6 \% \mathrm{AT}$, the most AT-rich coding region of which we are aware. The 
yeast mitochondrial genome is generally considered to be organized as "genes" flanked by AT-rich "spacer DNA" (Bernardi, 1976), the latter comprising some $50 \%$ of the total mitochondrial genome. Widely dispersed along the yeast mitochondrial genome are GC-rich clusters (Prunell and Bernardi, 1977), and it has been suggested that these short ( $30-50 \mathrm{bp}$ ) palindromic sequences punctuate genes and serve as sites for RNA processing (Tzagoloff et al., 1980). Our present results, together with the observation that stable var1 transcripts retain such GC-rich sequences (Zassenhaus et al., manuscript in preparation), require some reevaluation of these models, which assign coding functions only to regions of moderate GC content, and spacer and control functions, respectively, to ATrich and GC-rich regions. We note that about $30 \%$ of the yeast mitochondrial genome $(24 \mathrm{~kb})$ has not yet been examined for coding regions because its high AT content appeared to exclude structural genes.

\section{Experimental Procedures}

\section{Cells and DNA Preparation}

S. cerevisiae petite strain A17-10 was described by Vincent et al. (1980) and obtained from P. S. Perlman. It transmits the var1[40.0] allele in crosses with tester strains. Strain DS401 $\left(\rho^{-}\right)$, derived from D273-10B, was used by Tzagoloff et al. (1980) for their sequencing studies; it was obtained from A. Tzagoloff and was shown by us to transmit the var1[42.0] allele. Cells were grown to late stationary phase in medium containing $1 \%$ yeast extract, $2 \%$ peptone, $2 \%$ dextrose and harvested by centrifugation. Mitochondrial DNA was isolated as described by Hudspeth et al. (1980).

\section{Labeling of DNA}

Restriction enzymes were obtained from New England BioLabs or Bethesda Research Laboratories and were used with the reaction conditions recommended by the manufacturers. We carried out multiple digests sequentially, where possible starting with the enzyme requiring the lowest salt and/or $\mathrm{Mg}^{2+}$ concentration, and supplementing the digest before addition of subsequent enzymes. Polynucleotide kinase was obtained from P-L Laboratories or Bethesda Research Laboratories. Alkaline phosphatase (BAPC) was from Worthington. It was dialyzed overnight at $4^{\circ} \mathrm{C}$ against $20 \mathrm{mM}$ Tris-

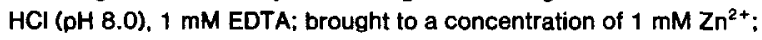
heated at $80^{\circ} \mathrm{C}$ for $20 \mathrm{~min}$; cooled on ice for 5-10 min; and centrifuged for $5 \mathrm{~min}$ at $12,800 \times \mathrm{g}$. The supernatant was brought to a concentration of $20 \%-25 \%$ glycerol and stored at $-20^{\circ} \mathrm{C}$. Escherichia coli DNA polymerase I (large fragment) was obtained from New England Nuclear. $\gamma^{32}$ P-ATP (4000-7000 Ci/mmole) was purchased from ICN or Amersham; $\alpha^{32}{ }^{32} \mathrm{P}$-deoxynucleoside triphosphates $(3000$ $\mathrm{Ci} / \mathrm{mmole}$ ) were from Amersham.

Restriction fragments were labeled at either their $5^{\prime}$ or $3^{\prime}$ ends for DNA sequencing. $5^{\prime}$ labeling was carried out as described by Maxam and Gilbert (1980). In some cases, all restriction cuts with two or more enzymes were made before end labeling to allow the digest to be checked for completion by electrophoresis through $1 \%$ agarose (in $40 \mathrm{mM}$ Tris base, $5 \mathrm{mM}$ sodium acetate, $1 \mathrm{mM}$ EDTA [pH 8.2]) or $4 \%$ polyacrylamide (in $40 \mathrm{mM}$ Tris base, $20 \mathrm{mM}$ sodium acetate, 2 mM EDTA [pH 7.8]) gels. In these cases, the ends to be labeled were produced with the first enzyme and dephosphorylated. Alkaline phosphatase was removed by deproteinization with phenol, then with phenol plus chloroform ( $1: 1$ ), and the DNA was precipitated with $67 \%$ ethanol from a $0.3 \mathrm{M}$ sodium acetate solution. The precipitated DNA was washed and redissolved in the reaction mixture for the next enzyme, and restriction was continued. The final digest was 5 '-labeled. With this protocol, ends predicted to be unlabeled were found to be so.
For $3^{\prime}$ labeling, DNA was incubated for $30-45 \mathrm{~min}$ at $0^{\circ} \mathrm{C}$ in 67 $\mathrm{mM}$ Tris- $\mathrm{HCl}(\mathrm{pH} 7.4), 7 \mathrm{mM} \mathrm{MgCl}, 67 \mathrm{mM} \mathrm{NaCl}, 200 \mu \mathrm{M}$ each of unlabeled deoxynucleoside triphosphates and $0.2 \mathrm{mCl}$ labeled triphosphate plus $0.16 \mathrm{U} / \mu \mathrm{g}$ DNA of DNA polymerase I large fragment.

\section{lsolation of End-Labeled DNA Fragments}

Fragments were separated after secondary cleavages in $4 \%$ polyacrylamide gels. For strand separation. fragments were run through $4 \%, 5 \%$ or $6 \%$ polyacrylamide gels in TBE buffer $(25 \mathrm{mM}$ Tris-borate, $0.5 \mathrm{mM}$ EDTA [pH 8.3]). For either type of end separation, fragments containing regions of interest were excised and embedded in $0.6 \%$ agarose (in TBE buffer plus $1 \mu \mathrm{g} / \mathrm{ml}$ ethidium bromide) on a horizontal gel apparatus. Troughs were cut on one side of the fragment, and the DNA was subjected to electrophoresis into several changes of TBE buffer by $30-60$ sec pulses of power at $300 \mathrm{~V}$. Samples containing DNA were pooled and precipitated from $0.1 \mathrm{M}$ ammonium acetate by 2.5 volumes of ethanol. Gel debris was removed by centrifugation, and contaminating acrylamide was removed by serial precipitations from water until the DNA remained in the supernatant. DNA from the final supernatant was precipitated by 2.5 volumes of ethanol after the addition of ammonium acetate to a concentration of $50 \mathrm{mM}$. For sequencing, the DNA was then resuspended in water.

\section{DNA Sequencing}

Sequencing was carried out according to the method of Maxam and Gilbert (1980), with several modifications. Ammonium acetate was used in place of sodium acetate for all precipitations. In addition to the hydrazine reactions for pyrimidine cleavage (and, later, in place of them), the permanganate $T$ and hydroxylamine $C$ reactions (Rubin and Schmid, 1980) were used. Furthermore, a citrate $\mathbf{G}+\mathbf{A}$ reaction (A. Maxam, personal communication) was carried out in $30 \mu$ by mixing, at $0^{\circ} \mathrm{C}, 16 \mu \mathrm{l} 50 \mathrm{mM}$ citrate $(\mathrm{pH} 4.0), 0.1 \mathrm{mM}$ EDTA with water and labeled DNA. After incubation for $5 \mathrm{~min}$ at $80^{\circ} \mathrm{C}$, piperidine release was carried out according to the method of Maxam and Gilbert (1980). Gels were $80 \mathrm{~cm}$ long by $0.4 \mathrm{~mm}$ thick, and usually contained either $6 \%$ or $11 \%$ acrylamide. Kodak XR-P film was exposed at $-70^{\circ} \mathrm{C}$, with Dupont Lightning Plus intensifying screens when necessary.

\section{Purification of var1 Protein}

Mitochondria and mitochondrial ribosomal subunits were isolated from strain $D^{\prime}$ as previously described (Terpstra and Butow, 1979), with the following modifications: cells were converted to spheroplasts by incubation with $0.3 \mathrm{mg}$ Zymolyase (Miles) per gram (wet weight) of cells; mitochondrial lysis and initial fractionation of ribosomal subunits were carried out according to the procedure of Singh et al. (1978); and 385 ribosomal subunits were isolated from a $15 \%-30 \%$ exponential sucrose gradient following centrifugation in a Beckman SW28 rotor for $12 \mathrm{hr}$ at $28,000 \mathrm{rpm}$.

The proteins of the small mitochondrial ribosomal subunit were separated on preparative $11 \%$ SDS gels (Douglas and Butow, 1976). The gels were stained for 30-45 sec in ice-cold $0.25 \mathrm{M} \mathrm{KCl}$ and 1 $\mathrm{mM}$ dithiothreitol as described by Hager and Burgess (1980). Strips cut from the gel containing var1 protein were soaked for 20 min at room temperature in $50 \mathrm{mM}$ Tris- $\mathrm{Cl}$ (pH 6.8), 2\% SDS, 2 mM EDTA and $1 \% 2$-mercaptoethanol. The strips were overlaid on $6.5 \%$ SDS gels and subjected to electrophoresis at $12 \mathrm{~mA}$ per gel for $16 \mathrm{hr}$. After staining and excising the var 1 band as described above, we soaked the strips for $10 \mathrm{~min}$ in $1 \mathrm{mM}$ dithiothreitol. Var1 was eluted by diffusion into $10 \mathrm{mM}$-ethylmorpholine acetate $(\mathrm{pH} \mathrm{6.8)}, 0.1 \%$ lithium dodecyl sulfate, $2 \%$ thlodiglycol and $2 \mathrm{mM}$ dithiothreitol for 48 $\mathrm{hr}$ at $37^{\circ} \mathrm{C}$, and was concentrated from the elution buffer with an Isco Sample Concentrator (model 1750). Different preparations of purified var1 protein were combined and subjected to electrophoresis a second time through a $6.5 \%$ SDS gel, eluted and concentrated as described above. The purified var1 protein was dialyzed against 50 $\mathrm{mM}$ ammonium bicarbonate and stored frozen.

\section{Amino Acid Analyeis}

Samples of vart protein were hydrolyzed for $15,24,48$ or $72 \mathrm{hr}$ under reduced pressure in constantly boiling $6 \mathrm{~N} \mathrm{HCl}$ at $110^{\circ} \mathrm{C}$. 
Amino acid analyses were pertormed with an Aminco Aminalyzer. Blanks, baselines and standards were run for each analysis. Except for losses in serine and threonine, the $\mathbf{4 8}$ and $72 \mathrm{hr}$ hydrolyses gave essentially the same results as the 15 and $24 \mathrm{hr}$ experiments. A comparison between the predicted and experimentaily determined amino acid compositions of var1 to estimate the extent of sequence homology was made with the expression:

$D T=1 / 2 \Sigma\left|n_{i A}-n_{i B}\right|$

(Cornish-Bowden, 1978), where DT, the "difference total," represents a quantity that has a minimum value of zero when the amino acid compositions of identical proteins are compared, and $n_{i A}$ and $n_{i B}$ represent the numbers of the $i$ th amino acid in protein $A$ and protein $B$, respectively.

\section{Two-Dimensional Gel Analysis of Ribosomal Proteins}

Proteins were extracted from the small mitochondrial ribosomal subunit after resuspension of the subunits in $30 \mathrm{mM}$ 2-mercaptoethanol, $0.25 \mathrm{M}$ EDTA, $6 \%$ thiodiglycol and $1 \mathrm{mM}$ phenylmethane sulfonyl fluoride by addition of 0.1 volume of $1 \mathrm{M} \mathrm{MgCl}_{2}$ and 2 volumes of glacial acetic acid. The RNA precipitate was removed by centrifugation, and the supernatant was desalted on a Sephadex G-25 column equilibrated with $1 \%$ acetic acid. Fractions containing the ribosomal proteins were pooled and lyophilized. The first gel dimension was a modification of the Triton-acid urea gel described by Zweidler (1978). The gel, cast in a $0.3 \times 10.5 \mathrm{~cm}$ tube, contained $8 \mathrm{M}$ urea, $8 \%$ polyacrylamide, $0.64 \%$ bisacrylamide, $0.37 \%$ Triton $X-100,5 \%$ acetic acid, $0.5 \%$ TEMED and $0.6 \%\left(\mathrm{NH}_{4}\right)_{2} \mathrm{~S}_{2} \mathrm{O}_{8}$. After pre-electrophoresis of $20 \mu \mathrm{l}$ of $2 \mathrm{M}$ cystamine in $5 \%$ acetic acid, the ribosomal proteins were applied in $10 \mu \mathrm{l}$ of $8 \mathrm{M}$ urea and $5 \%$ acetic acid. Electrophoresis was carried out for $4.5 \mathrm{hr}$ at $140 \mathrm{~V}$. The gel was removed and soaked in $0.5 \mathrm{M}$ Tris ( $\mathrm{pH} \mathrm{6.8)}$ ) and 1\% SDS for $45 \mathrm{~min}$, and the proteins were subjected to electrophoresis in a second dimension on an $11 \%$ SDS gel. Gels were fixed and stained as described by Terpstra et al. (1979).

\section{Acknowledgments}

These studies were supported by grants from the National Institutes of Health and the Robert A. Welch Foundation. We thank Rober Lersch for help with several experiments, Philip S. Perlman for helpful discussions, Robert A. Bender and Gordon P. Moore for critical readings of the manuscript and Suzanne Rutledge, Barbara L. Smith and Katherine Sandberg for help with preparation of the manuscript. Stephen Anderson kindly provided the sequence of bovine mitochondrial DNA in advance of publication. We are particularly grateful to Brent Reed for his help with the amino acid analysis.

The costs of publication of this article were defrayed in part by the payment of page charges. This article must therefore be hereby marked "advertisement"' in accordance with 18 U.S.C. Section 1734 solely to indicate this fact.

Received May 28, 1982

\section{References}

Anderson, S., Bankier, A. T., Barrell, B. G., de Bruijn, M. H. L. Coulson, A. R., Drouin, J., Eperon, I. C., Nierlich, D. P., Roe, B. A., Sanger, F., Schreier, P. H., Smith, A. J. H., Staden, R. and Young, I. G. (1981). Sequence and organization of the human mitochondrial genome. Nature 290, 457-465.

Anderson, S., de Bruijn, M. H. L., Coulson, A. R., Eperon, I. C., Sanger, F, and Young, I. G. (1982). The complete sequence of bovine mitochondrial DNA: conserved features of the mammalian mitochondrial genome. J. Mol. Biol., in press.

Attardi, G., Cantatore, P., Ching, E., Crews, S., Gelfand, R., Merkel, C., Montoya, J. and Ojala, D. (1980). The remarkable features of gene organization and expression of human mitochondrial DNA. In The Organization and Expression of the Mitochondrial Genome, A. M. Kroon and C. Saccone, eds. (Amsterdam: Elsevier/North-Holland Biomedical Press). pp 103-119.
Barrell, B. G. Bankier, A. T. and Drouin, J. (1979). A different genetic code in human mitochondria. Nature 282, 189-194.

Bernardi, G. (1976). Organization and evolution of the mitochondria genome of yeast. J. Mol. Evol. 9, 25-35.

Bibb, M. J., Van Etten, R. A., Wright, C. T., Walberg, M. W. and Clayton, D. A. (1981). Sequence and gene organization of mouse mitochondrial DNA. Cell 26, 167-180.

Bonitz, S. G., Berlani, R., Coruzzi, G., Li, M., Macino, G., Nobrega, F. G., Nobrega, M. P., Thalenfeld, B. E. and Tzagoloff, A. (1980a) Codon recognition rules in yeast mitochondria. Proc. Nat. Acad. Sci USA 77, 3167-3170.

Bonitz, S. G., Coruzzi, G., Thalenfeld, B. E., Tzagoloff, A. and Macino, G. (1980b). Assembly of the mitochondrial membrane system: struc ture and nucleotide sequence of the gene coding for subunit 1 of yeast cytochrome oxidase. J. Biol. Chem. 255, 11927-11941.

Browning, K. S. and RajBhandary, U. L. (1982). Cytochrome oxidase subunit III gene in Neurospora crassa mitochondria. Location and sequence. J. Biol. Chem. 257, 5253-5256.

Butow, R. A., Farrelly, F., Zassenhaus, H. P., Hudspeth, M. E. S. Grossman, L. I. and Perlman, P. S. (1982) Var1 determinant region of yeast mitochondrial DNA. In Mitochondrial Genes, G. Attardi, P. Borst and P. P. Sloninski, eds. (Cold Spring Harbor, New York: Cold Spring Harbor Laboratory Press), pp. 241-253.

Cornish-Bowden, A. (1978). Interpretation of the difference index as a guide to protein sequence identity. J. Theor. Biol. 74, 155-161.

Coruzzi, G. and Tzagoloff, A. (1979). Assembly of the mitochondrial membrane system: DNA sequence of subunit 2 of yeast cytochrome oxidase. J. Biol. Chem. 254, 9324-9330.

Coruzzi, G., Bonitz, S. G., Thalenfeld, B. E. and Tzagoloff, A. (1981). Assembly of the mitochondrial membrane system: analysis of the nucleotide sequence and transcripts in the oxi1 region of yeast mitochondrial DNA. J. Biol. Chem. 256, 12780-12787.

Douglas, M. G. and Butow, R. A. (1976). Variant forms of mitochondrial translation products in yeast: evidence for location of determinants on mitochondrial DNA. Proc. Nat. Acad. Sci. USA 73, 10831086

Dujon, B. (1980). Sequence of the intron and flanking, exons of the mitochondrial $21 \mathrm{~S}$ rRNA gene of yeast strains having different alleles at the $\omega$ and rib-1 loci. Cell 20, 185-197.

Farrelly, F., Zassenhaus, H. P. and Butow, R. A. (1982). Characterization of transcripts from the vart region on mitochondrial DNA of Saccharomyces cerevisiae. J. Biol. Chem. 257, 6581-6587.

Fox, T.D. (1979). Five TGA "stop" codons occur within the translated sequence of the yeast mitochondrial gene for cytochrome $c$ oxidase subunit II. Proc. Nat. Acad. Sci. USA 76, 6534-6538.

Fox, T. D. and Leaver, C. J. (1981). The Zea mays mitochondrial gene coding cytochrome oxidase subunit II has an intervening sequence and does not contain TGA codons. Cell 26, 315-323.

Groot, G. S. P., Van Harten-Loosbroek, N. and Kreike, J. (1978). Electrophoretic behavior of yeast mitochondrial translation products. Biochim. Biophys. Acta 517, 457-463.

Groot, G. S. P., Mason, T. L. and Van Harten-Loosbroek, N. (1979) Vart is associated with the small ribosomal subunit of mitochondrial ribosomes in yeast. Mol. Gen. Genet. 174, 339-342.

Hager, D. A. and Burgess, R. R. (1980). Elution of proteins from sodium dodecyl sulfate-polyacrylamide gels, removal of sodium dodecyl sulfate, and renaturation of enzymatic activity: results with sigma subunit of Escherichia coli RNA polymerase. Anai. Biochem. 109, 76-86.

Hare, J. F., Ching, E. and Attardi, G. (1980). Isolation, subunit composition, and site of synthesis of human cytochrome oxidase. Biochemistry 19, 2023-2030.

Hudspeth, M. E. S., Shumard, D. S., Tatti, K. M. and Grossman, L. I. (1980). Rapid purification of yeast mitochondrial DNA in high yield. Biochim. Biophys. Acta 610, 221-228.

Lambowitz, A. M., Chua, N.-H. and Luck, D. J. L. (1976). Mitochondrial ribosome assembly in Neurospora: preparation of mitochondrial 
ribosomal precursor particles, site of synthesis of mitochondrial ribosomal proteins and studies on the poky mutant. J. Mol. Biol. 107, 223-253.

Lambowitz, A. M., LaPolla, R. J. and Collins, R. A. (1979). Mitochondrial assembly in Neurospora. Two-dimensional gel electrophoretic analysis of mitochondrial ribosomal proteins. J. Cell Biol. 82, 17-31. LaPolla, R. J. and Lambowitz, A. M. (1977). Mitochondrial ribosome assembly in Neurospora crassa: chloramphenicol inhibits the maturation of small ribosomal subunits. J. Mol. Biol. 116, 189-205.

LaPolla, R. J. and Lambowitz, A. M. (1981). Mitochondrial ribosome assembly in Neurospora crassa. Purification of the mitochondrially synthesized ribosomal protein, S-5. J. Biol. Chem. 256, 7064-7067. Lazowska, J., Jacq, C. and Slonimski, P. P. (1980). Sequence of introns and flanking exons in wild-type and box 3 mutants of cytochrome $b$ reveals an interlaced splicing protein coded by an intron. Cell 22, 333-348.

Lazowska, J., Jacq, C. and Slonimski, P. P. (1981). Splice points of the third intron in the yeast mitochondrial cytochrome $b$ gene. Cell 27, 12-14.

Lopez, I. C., Farrelly, F. and Butow, R. A. (1981). Trans action of the var1 determinant region on yeast mitochondrial DNA. J. Biol. Chem. 256, 6496-6501.

Macino, G. and Tzagoloff, A. (1979). Assembly of the mitochondrial membrane system: the DNA sequence of a mitochondrial ATPase gene in Saccharomyces cerevisiae. J. Biol. Chem. 254, 4617-4623. Macino, G. and Tzagoloff, A. (1980). Assembly of the mitochondrial membrane system: sequence analysis of a yeast mitochondrial ATP. ase gene containing the oli-2 and oli-4 loci. Cell 20, 507-517.

Maxam, A. and Gilbert, W. (1980). Sequencing end-labeled DNA with base-specific cleavage reactions. Meth. Enzymol. 65, 499-560.

Nobrega, F. G. and Tzagoloff, A. (1980). Assembly of the mitochondrial membrane system: DNA sequence and organization of the cytochrome b gene in Saccharomyces cerevisiae D273-10B. J. Biol. Chem. 255, 9828-9837.

Perasso, R., Curgy, J.-J., Iftode, F. and Andre, J. (1980). Interactions between mitochondria and their cellular environment in a cytoplasmic mutant of Tetrahymena pyriformis resistant to chloramphenicol. In The Organization and Expression of the Mitochondrial Genome, A. M. Kroon and C. Saccone, eds. (Amsterdam: Elsevier/North-Holland Biomedical Press), pp. 355-363.

Perlman, P. S., Douglas, M. G., Strausberg, R. L. and Butow, R. A. (1977). Localization of genes for variant forms of mitochondrial proteins on mitochondrial DNA of Saccharomyces cerevisiae. J. Mol. Biol. 115, 675-694.

Prunell. A. and Bernardi, G. (1977). The mitochondrial genome of wild-type yeast cells. IV. Genome organization. J. Mol. Biol. 110, 5374.

Rubin, C. M. and Schmid, C. W. (1980). Pyrimidine-specific chemical reactions useful for DNA sequencing. Nucl. Acids Res. 8, 46134619.

Sebald, W., Machleidt, W. and Otto, J. (1973). Products of mitochondrial protein synthesis in Neurospora crassa. Determination of equimolar amounts of three products in cytochrome oxidase on the basis of amino acid analysis. Eur. J. Biochem. 38, 311-324.

Sebald W. Sebald-Althaus, M. and Wachter, E. (1977). Altered amino acid sequence of the DCCD-binding protein of the nuclear oligomycinresistant mutant AP-2 from Neurospora crassa. In Mitochondria 1977, N. Bandlow, R. J. Scheweyen, K. Wolf and F. Kaudewitz, eds. (Berlin: de Gruyter), pp. 433-440.

Singh, A., Mason, T. L. and Zimmerman, R. A. (1978). A cold-sensitive cytoplasmic $50 S$ ribosomal subunit. Mol. Gen. Genet. 161, 143-151. Sor, F. and Fukuhara, H. (1980). Sequence nucleotidique du gene de l'ARN ribosomique 155 mitochondrial de la levure. CR Acad. Sci. Paris 291, 933-936.

Strausberg, R. L. and Butow, R. A. (1977). Expression of petite mitochondrial DNA in vivo: zygotic gene rescue. Proc. Nat. Acad. Sci. USA $74,2715-2719$.
Strausberg, R. L. and Butow, R. A. (1981). Gene conversion at the var1 locus on yeast mitochondrial DNA. Proc. Nat. Acad. Sci. USA 78, 494-498.

Strausberg, R. L., Vincent, R. D., Perlman, P. S. and Butow, R. A. (1978). Asymmetric gene conversion at inserted segments on yeast mitochondrial DNA. Nature 276, 577-583.

Tait, A., Knowles, J. K. C., Hardy, J. C. and Lipps, H. (1976). The study of the genetic function of Paramecium mitochondrial DNA using species hybrids. In Genetics and Biogenesis of Chloroplasts and Mitochondria, T. Bucher, W. Neupert, W. Sebald and S. Werner, eds. (Amsterdam: North-Holland), pp. 569-572.

Terpstra, P. and Butow, R. A. (1979). The role of var1 in the assembly of yeast mitochondrial ribosomes. J. Biol. Chem. 254, 12662-12669. Terpstra, P., Zanders, E. and Butow, R. A. (1979). The association of var1 with the 385 mitochondrial ribosomal subunit in yeast. J. Biol. Chem. 254, 12653-12661.

Thalenfeld, B. and Tzagoloff, A. (1980). Assembly of the mitochondrial membrane system: sequence of the oxi2 gene of yeast mitochondrial DNA. J. Biol. Chem. 255, 6173-6180.

Tzagoloff, A., Nobrega, M., Akai, A. and Macino, G. (1980). Assembly of the mitochondrial membrane system. Organization of yeast mitochondrial DNA in the oli1 region. Curr. Genet. 2, 149-157.

Vincent, R. D. (1982). Physical analysis of the var1 region of Saccharomyces cerevisiae mitochondrial DNA. Ph.D. thesis, The Ohio State University, Columbus, Ohio.

Vincent, R. D., Periman, P. S., Strausberg, R. L. and Butow, R. A (1980). Physical mapping of genetic determinants on yeast mitochondrial DNA affecting the apparent size of the var1 polypeptide. Curr. Genet. 2, 27-38.

Young, I. G. and Anderson, S. (1980). The genetic code in bovine mitochondria: sequence of genes for the cytochrome oxidase subunit II and two tRNAs. Gene 12, 257-265.

Zweidler, A. (1978). Resolution of histones by polyacrylamide gel electrophoresis in presence of nonionic detergents. Meth. Cell Biol. 17, 223-233. 